\section{BILE PERITONITIS IN INFANCY}

\author{
BY
}

F. DENIS HINDMARSH, M.S., F.R.C.S.

Temporary Assistant Surgeon, Royal Victoria Infirmary, Newcastle-upon-Tyne

So far as I have been able to ascertain this is the first case of bile peritonitis in infancy occurring without trauma to be reported in this country. Caulfield (1936) published two similar cases in America, and stated that severe trauma had caused rupture to the gall-bladder or common duct in all the reported cases he could find.

\section{Case Report}

The patient, a baby girl aged 1 year and 10 months, was admitted to the children's department of the Royal Victoria Infirmary on Nov. 28, 1946. The child had been well until 36 hours before admission. She woke her parents up in the early morning of the $27 \mathrm{th}$, was restless but did not cry. She had complete loss of appetite, and vomited once towards evening. Her bowels moved four times during the day, but the motions were apparently normal in colour. On the day of admission she again vomited, but slept fitfully and did not appear to be in much pain.

On admission at 7.30 p.m. she was collapsed, her extremities were cold and cyanotic, her respiration was rapid, but her chest showed no abnormal physical signs. The abdomen was slightly distended, with some generalized tenderness. The child's condition was so poor that it was decided to give an intravenous transfusion of plasma and to re-examine her when some improvement had occurred. Consequently $200 \mathrm{ml}$. of plasma was given in about two hours, by which time her condition was much improved. A further examination showed a somewhat distended abdomen, with generalized tenderness, especially in the upper abdomen. There were diminished resonance in the flanks and tenderness per rectum. The temperature was $103^{\circ} \mathrm{F}$. $\left(39.4^{\circ} \mathrm{C}\right.$ ), pulse 150 , and respirations 50. The white cell count was 31,500 per c.mm. A diagnosis of peritonitis, probably associated with appendicitis, was made.

The abdomen was opened through a right paramedian paraumbilical incision. A large quantity of bile-stained fluid escaped from the peritoneal cavity; this was not measured, but it was estimated to be about $400-500 \mathrm{ml}$. The incision was enlarged upwards, and a rapid inspection of the gallbladder and common duct did not reveal any gross abnormality. There was some retroperitoneal oedema, and flecks of lymph were present in the region of the duodenum. As the child's condition was not very satisfactory simple drainage in the region of the common duct was performed. Culture of the bile proved sterile. The origin of the bile being uncertain it was decided to aspirate the stomach post-operatively, giving $100 \mathrm{ml}$. of saline every three hours intravenously. This treatment was continued until Nov. 30. Bile was still draining from the wound. The drainage-tube was removed on the seventh postoperative day, and by Dec. 10 the wound was almost healed and the bile drainage had cleared up.

The patient was discharged from hospital on Dec. 11, but was readmitted on Jan. 2, 1947, complaining of abdominal pain and vomiting; this, however, settled down very quickly. A cholecystogram revealed a gall-bladder which seemed to function normally. The child was discharged again, apparently well, on Jan. 8.

\section{Discussion}

Bile peritonitis following trauma to the liver is relatively common. I saw two cases due to bomb-splinter wounds while serving with a field surgical unit. Both these cases recovered. I have also seen bile peritonitis associated with crush injury and laceration of the liver; this patient survived the onset of bile peritonitis but subsequently died of uraemia.

Most surgeons have seen a case of bile peritonitis in adults without apparent cause. One case reported to me by Mr. T. A. Hindmarsh (personal communication) had two such attacks, separated by an interval of seven years' normal health. It is certainly not the fatal condition it is sometimes said to be, unless it is associated with gall-bladder disease.

It is thought that in the above case there must have been a small cyst or aberrant duct which had ruptured; the abnormality must have been a minor one, as recovery was rapid and apparently complete. As an alternative cause, in view of the retroperitoneal oedema, I considered the possibility of a duodenal saccule which had ruptured, but the subsequent behaviour of the case ruled this out of court. Remarkable features are the leucocytosis and the pyrexia, suggesting an inflammatory cause; as already stated, however, the bile was sterile.

Caulfield's cases were somewhat similar to the above case: both his cases occurred in male infants under six months old, but the onset was more gradual, the babies had no abnormal temperature, and they were jaundiced. It is interesting to notice that in the surviving case simple drainage in the region of the common duct, such as I performed, was sufficient apparently to cure the condition. Caulfield came to the same conclusion-that there must have been some minor abnormality of the ducts. In his other case no operation was performed, and it was found post mortem that there was a congenital stricture of the common duct.

\section{Summary}

A case of bile peritonitis in early childhood is described. It is claimed to be the first reported case in this country. Simple drainage in the region of the common duct effected an apparent cure.

The possible aetiology of the case is discussed.

Comparison is made with Caulfield's cases.

I would like to thank Prof. J. C. Spence for permission to publish this case, and Miss M. Swinburne and other members of the Children's Department for their co-operation in the pre- and postoperative treatment.

REFERENCE

Caulfield, E. (1936). Amer. J. Dis. Child., 52, 1348.

\section{THE BERGER-KHAN TEST FOR SYPHILIS}

\author{
BY
}

J. H. FODDEN, M.D.

AND

E. J. MADDOX, F.I.M.L.T.

(From the Donaldson-Hudson Pathological Laboratories, Shrewsbury)

Whilst using the dye isamine blue as an indicator in serological tests for syphilis Berger (1943) found that certain other dyes when mixed with a suitable alcoholic heart extract caused, in syphilitic sera, not only the formation of coloured precipitates but an increase in the sensitivity of the reaction. This sensitivity was directly proportional to the amount of dye present in the antigen. Janus green and Victoria blue were the dyes of choice, as they appeared to be the best sensitizers and in their presence heavy flocculation rapidly occurred. The precipitate was intensely coloured and took up all the dye from the solution, leaving a water-clear supernatant fluid. Sera containing amounts of syphilis antibody too small to react with a given antigen without dye showed marked flocculation in the presence of Victoria blue or Janus green. Berger pictured the sensitizing action of the dye as an antibody-like effect which had been deprived of its specificity and which was 
conditioned by the presence of a specific factor in syphilitic serum. In the dye test he devised for syphilis Berger chose Victoria blue because very fine dispersion of the alcoholic antigen could be obtained with this dye as compared with Janus green.

For the purpose of the investigation this laboratory carried out in triplicate 970 routine serological tests for syphilis. The washed-antigen method of Price (1946) was also used for a short time, but in our hands appeared to be too sensitive. We therefore discontinued parallel tests to avoid undue complications in the interpretation of results.

The standard antigen for the Kahn test as supplied by the Ministry of Health Special Laboratories was used. The preparation of reagents and the technique of the test as recommended by Berger were carried out in the following manner.

A stock antigen (which keeps for at least a year at room temperature) is prepared thus: To 10 parts of standard antigen containing $0.6 \%$ of cholesterol and having a titre of $1+1.2$ add 1 part of tinct. benz. co. B.P. To $10 \mathrm{ml}$. of this mixture add $17 \mathrm{mg}$. of Victoria blue $4 \mathrm{R}$ (Gurr). The container should be kept well stoppered.

\section{Method of Test}

(1) Pipette 1 part of the stock antigen $(0.1 \mathrm{ml}$.) into the bottom of a dry tube. (2) Add 10 parts $(1 \mathrm{ml}$.) of $0.85 \%$ sodium chloride solution rapidly to the tube from the pipette. This dispersed antigen is sufficient for at least thirty tests, and can be used at once or during any time on the day of preparation. It should be shaken immediately before use. (3) Place on a prepared glass slide one drop of the serum to be tested and add a drop of equal size of the dispersed antigen. (4) Mix the drops with a glass rod, rock the slide for two minutes, and read results immediately. (Note : To help in the rapid handling of large numbers of sera use may be made of ordinary clear glass sheets with rows of rings painted on the surface. A convenient size would be 8 in: by 10 in. ( 20 by $25 \mathrm{~cm}$.), as this allows four rows of six rings, $1 \frac{1}{4}$ in. $(3.2 \mathrm{~cm}$.) in diameter, per plate. High-gloss black enamel has proved most useful and durable under test.) (5) The results are read macroscopically, and as a distinct aid to easy reading the slide is held over a sheet of white paper. Positive reactions show large deep-blue floccules easily visible in a water-clear fluid. Negatives at two minutes show no flocculation whatever, the mixed drop remaining quite homogeneous and of a sky-blue colour.

It is the custom in this laboratory when reading positive $\mathrm{Kahn}$ tests to assign to each result a numerical indicator to express the strength of the positive reaction as judged by the degree of flocculation. The standard Kahn method often showed lower numerical grading, and in the case of weak positives by the other methods some were missed. This was particularly marked when dealing with old treated cases. Difficulty in reading weakly positive standard Kahn tests is overcome in the Berger-Kahn test by the pronounced staining of the floccules which occurs. The strongly positive sera are easily read, as the floccules in this case are very large and absorb the whole of the dye. In our experience, whenever this result was obtained we always noticed that the Wassermann reaction read $2+$ or $3+$. We wish to emphasize that every one of our positive Wassermann results gave a positive reaction with the Berger-Kahn test.

We are at present observing the results of this method upon cerebrospinal fluid from cases of neurological syphilis and hope to report separately upon a series of such tests.

\section{Comment}

The reaction should be read at two minutes, and not four minutes as recommended by Berger, as reading at the latter time yields a high proportion of mixtures showing very faint granularity, which can lead to some confusion.

Berger made no reference to the graduation in size of the blue floccules in assessing the strength of a positive result. We found it quite easy to grade positives on the size of particles given by the Berger-Kahn test. We found such gradation in particle size very constant and most helpful.

REFERENCES

Berger, F. M. (1943). Brit. J. exp. Path., 24, 252.

Price, I. N. Orpwood (1946). Mon. Bull. Min. Hlth., 5, 43.

\section{Medical Memoranda}

\section{Arsenical Dermatitis Successfully Treated with BAL}

As the treatment of this condition has always been difficult and rather unsatisfactory I thought these two cases worth recording.

\section{Case Reports}

Case 1.-A labourer aged 27 first attended the V.D. clinic at the Royal Victoria and West Hants Hospital, Bournemouth, on June 12, 1946. He then had a large ulcer at the base of the glans penis, and dark-ground examination revealed the presence of Treponema pallidum. The Wassermann reaction was negative. Treatment was started at once with 300,000 units of penicillin twice daily for five days, together with N.A.B. and bismuth. He was given $0.45 \mathrm{~g}$. of N.A.B. twice weekly for four injections, followed by $0.6 \mathrm{~g}$. twice weekly for a further eight injections-a total of $6.6 \mathrm{~g}$. of arsenic. Bismuth, $0.2 \mathrm{~g}$. twice weekly, was given for six weeks, total $2.4 \mathrm{~g}$. The full course was completed on Aug. 17. On Aug. 28 an erythematous rash with desquamation appeared on the limbs and trunk. The patient was given daily intravenous injections of $6 \mathrm{ml}$. of calcium thiosulphate. There was no improvement on Sept. 4; he then had oedema of the hands, fissuring of the palms with some exfoliation, and similar fissures at the ankles and on the soles of the feet. There was oozing from all fissures. On Sept. 5 treatment with $2 \mathrm{ml}$. of BAL (British anti-lewisite) intramuscularly every four hours was started. The next three days he had $2 \mathrm{ml}$. twice a day, and then $2 \mathrm{ml}$. a day for two days. On Sept. 11 there was no desquamation and the fissures were drying up. On the 18th the oedema of the hands was much less and the fissures were healing well. On the 25th there were slight cracks on the palms of the hands and soles of the feet. By Oct. 9 the hands and feet were quite healed and the patient was back at work.

Case 2.-A housewife aged 26 first attended the V.D. clinic on Sept. 18, 1946, with a secondary syphilitic rash involving the arms and trunk (Wassermann,++ Kahn +++ ). There was some dental sepsis, but as she was seven months pregnant it was thought advisable to prescribe arsenic and bismuth as well as penicillin. She was given 600,000 units of penicillin daily from Sept. 25 to Oct. 1 ; three injections of $0.45 \mathrm{~g}$. and five of $0.6 \mathrm{~g}$. of N.A.B. (a total of $4.35 \mathrm{~g}$. of arsenic) and eight injections of $0.2 \mathrm{~g}$. of bismuth between Sept. 25 and Oct. 23 . On Oct. 30 erythematous patches with oedema were noticed on the buttocks, and smaller patches were seen at the bends of the elbows. Calcium thiosulphate, $6 \mathrm{ml}$., was prescribed twice weekly till Nov. 15. As there was no improvement BAL was given from Nov. 22 to 25 . Owing to her confinement the patient did not attend again until Jan. 22, 1947, when no fash was to be seen, and she stated that it had quite disappeared before her confinement on Dec. 17

It seems to me that BAL may well be the answer to the syphilologist's prayer, for, instead of cases of arsenical dermatitis being in hospital for weeks at a time, they may now be treated as out-patients. The response is most dramatic, as the rash begins to clear as soon as treatment is started.

I would like to thank Dr. R. H. S. Thompson, of the Department of Biochemistry, Oxford, for his help and interest, and for supplying the BAL; also my colleague, Dr. L. Heasman, for his help in treating these cases.

J. Lawrence ReEVE, M.R.C.S., L.R.C.P., Director of Venereal Diseases Clinic.

Royal Victoria and West Hants Hospital, Bournemouth. 